\title{
Aerogel-Based $\mathrm{TiO}_{2}$ Stable Inks for Direct Inkjet Printing of Nanostructured Layers
}

\author{
Aline M. Barreiro, ${ }^{1}$ Geneviève K. Pinheiro, ${ }^{2}$ Bruno N. Wesling, ${ }^{2}$ Daliana Müller, ${ }^{1}$ \\ Letícia T. Scarabelot, ${ }^{2}$ Luciana V. de Souza, ${ }^{1}$ Dachamir Hotza $(1),{ }^{1,3}$ and Carlos R. Rambo $\mathbb{1}^{1,2}$ \\ ${ }^{1}$ Graduate Program on Materials Science and Engineering (PGMAT), Federal University of Santa Catarina (UFSC), \\ Florianópolis 88040-900, Brazil \\ ${ }^{2}$ Department of Electrical and Electronic Engineering (EEL), Federal University of Santa Catarina (UFSC), \\ Florianópolis 88040-900, Brazil \\ ${ }^{3}$ Department of Chemical and Food Engineering (EQA), Federal University of Santa Catarina (UFSC), \\ Florianópolis 88040-900, Brazil
}

Correspondence should be addressed to Carlos R. Rambo; carlos.rambo@ufsc.br

Received 3 April 2020; Revised 10 July 2020; Accepted 15 July 2020; Published 30 July 2020

Academic Editor: Michele Fedel

Copyright (c) 2020 Aline M. Barreiro et al. This is an open access article distributed under the Creative Commons Attribution License, which permits unrestricted use, distribution, and reproduction in any medium, provided the original work is properly cited.

\begin{abstract}
Inkjet printing presents a high potential for cost reduction of electronic devices manufacturing due to the capacity to deposit materials with high precision, less material waste, and large-scale production through the roll-to-roll printing processes. In this work, a nanostructured $\mathrm{TiO}_{2}$ ink was developed using $\mathrm{TiO}_{2}$ aerogel and an alkaline aqueous solution, which resulted in a very stable suspension. A high-intensity ultrasonic mixer was used to fragment and disperse $\mathrm{TiO}_{2}$ aerogels producing suspensions with particles smaller than $200 \mathrm{~nm}$, which are suitable for the inkjet printing process. For the development of the ink, the viscosity and surface tension were adjusted by using glycerol and a surfactant (Triton X-100). The influence of those components on the properties of the ink was evaluated for different concentrations. After formulation of the inks, the printing parameters were adjusted to optimize the process. Films with high surface area and less than $100 \mathrm{~nm}$ grain size were successfully produced. Electrical measurements revealed a resistive-like behavior with the sheet resistance increasing with number of printed layers.
\end{abstract}

\section{Introduction}

Inkjet printing process has been considered a very promising technique due to high precision deposition, low processing temperatures, and low consumption of material. Moreover, this might be a competitive technology due to the possibility of using flexible and low cost materials, and due to the high production speeds by roll-to-roll printing.

Titanium dioxide $\left(\mathrm{TiO}_{2}\right)$ is a semiconductor widely used in electronic and optoelectronic devices like perovskite-type solar cells and dye sensitized solar cells (DSSC), which generally have a compact layer of $\mathrm{TiO}_{2}$, followed by a thicker and porous $\mathrm{TiO}_{2}$ layer applied by different deposition methods [1-4]. Pinheiro et al. [4] deposited a $\mathrm{TiO}_{2}$ aerogel layer as an electron-transport layer in $\mathrm{CH}_{3} \mathrm{NH}_{3} \mathrm{PbI}_{3}$-based solar cells, which enabled deposition of a higher concentration of perovskite, enhancing layers interpenetration. Bernacka-Wojcik et al. [5] have analyzed the performance of inkjet printed DSSC using inks based on commercial $\mathrm{TiO}_{2}$ pastes and compared the results with the conventional "doctor blade" deposition technique. The devices produced via inkjet printing presented higher effective electron diffusion length due to increased contact area between $\mathrm{TiO}_{2}$ and the dye. $\mathrm{TiO}_{2}$ has also been investigated for protective layer between a transparent conducting oxide (TCO) and the electrolyte, increasing the life time of the solar cells. In this case, a dense $\mathrm{TiO}_{2}$ layer of $\sim 50 \mathrm{~nm}$ is deposited directly on the substrate containing the TCO layer, protecting it from the contact with the electrolyte solution [1-3]. In the inkjet printing process, the production of high quality electronic 
and optoelectronic devices requires the use of stable inks with adequate properties to the printer requirements [6]. Therefore, the ink formulation has as main guidelines the specifications provided by the printer manufacturer, involving particle size, $\mathrm{pH}$, viscosity, and surface tension. The particle size depends on the methods of synthesis and dispersion of $\mathrm{TiO}_{2}$ and usually involves sol-gel or mechanical dispersion techniques $[7,8]$. Mechanical dispersion of nanometric powders through grinding in a liquid medium has hindrances because the nanoparticles are strongly bonded and do not break up easily, although this is a widely used technique. Kuscer et al. have used ball-milling for the formulation of $\mathrm{a} \mathrm{TiO}_{2}$ ink; and, after $5 \mathrm{~h}$, the average particle size (D50) was reduced from 600 to $170 \mathrm{~nm}$ [8]. Ultrasonic (US) irradiation is also a widely used technique for dispersion of colloidal suspensions and is considered very effective. The US irradiation produces shock waves that form microscopic bubbles and cavitation, causing collision between particles. Under conditions that favor the dispersion medium, the agglomerates can be broken, reducing the size of the suspended particles [9].

This work aims to develop a nanostructured ink based on $\mathrm{TiO}_{2}$ aerogels for printing high surface area $\mathrm{TiO}_{2}$ layers. Aerogels are complex nanostructured materials with an extremely porous structure, low density, and high surface area. Due to its high porosity and low connectivity between particles, $\mathrm{TiO}_{2}$ aerogels are very fragile and can be easily fragmented. When this material was immersed into an alkaline aqueous media and dispersed through high intensity ultrasonic processing, it resulted in a very stable suspension with reduced particle size and was applicable to inkjet printing. The remaining procedures for the ink formulation involve adjustments of the ink properties and printing parameters as well as the analysis of the interaction between the ink and the substrate aiming to obtain high quality printed layers.

\section{Materials and Methods}

Titania aerogels were prepared by the modified sol-gel route proposed in [10]. Briefly, titanium trichloride $\left(\mathrm{TiCl}_{3}, \mathrm{Vetec}\right)$ was dissolved in $10 \mathrm{~mL}$ of absolute ethanol. Four drops of acetic anhydride were gently added under stirring. After complete homogenization of the solution, $4 \mathrm{~mL}$ of propylene oxide were added. After pouring the solution on molds, gelation occurred in a few minutes. The obtained gels were removed from the molds and immersed in ethanol for $24 \mathrm{~h}$. In order to prepare the gel for supercritical drying, the immersion solvent was gradually substituted by acetone, every $24 \mathrm{~h}$ during 5 days. After this period, the material was dried in a $\mathrm{CO}_{2}$ supercritical dryer (SPI-Dry Critical Point Dryer) to obtain the $\mathrm{TiO}_{2}$ aerogels. After calcination at $400^{\circ} \mathrm{C}$ for $4 \mathrm{~h}, \mathrm{X}$-ray diffraction (XRD, X-Pert, Phillips) was carried out to identify the crystalline phases of $\mathrm{TiO}_{2}$ using a $\mathrm{Cu} \mathrm{K \alpha}$ radiation $(\lambda=1.54 \AA)$ and scanning over a $2 \theta$ interval between $5^{\circ}$ and $90^{\circ}$ with steps of $1^{\circ} / \mathrm{min}$. Transmission Electronic Microscopy (TEM, JEM-1011, $100 \mathrm{kV}$ ) images were obtained to analyze the aerogels microstructure. The specific surface area of the calcined aerogels was determined by multipoint B.E.T. (Nova 1200e, Quanta Chrome) through nitrogen adsorption-desorption isotherms. In order to promote the stability of the suspension, the water $\mathrm{pH}$ was adjusted to 9 by gradually adding $\mathrm{NH}_{4} \mathrm{OH}$ and simultaneously measuring the $\mathrm{pH}$ of the solution. In the prepared media, 0.5 wt. $\% \mathrm{TiO}_{2}$ aerogel was added, followed by conventional US homogenization. The obtained aqueous $\mathrm{TiO}_{2}$ suspensions were then submitted to a high intensity ultrasonic processor for $1,3,5,7$, and $10 \mathrm{~min}$ in order to reduce the average particle size. In this process, ultrasound is applied at intervals of $1 \mathrm{~min}$ avoiding excessive heating. After dispersion, the particle size of the samples was analyzed by Dynamic Light Scattering (DLS, Zetasizer-Nanosizer Zen 3600, Malvern). The viscosity and the surface tension of the suspensions were adjusted by adding glycerol and Triton X-100 (Sigma-Aldrich), respectively [9]. The influence of glycerol content on the ink viscosity was analyzed in a viscometer (DC 10, Thermo Haake), with glycerol content ranging from 5 to $30 \mathrm{wt} . \%$. The surface tension of the inks with different additive contents $(0.3,0.5$, and $1 \mathrm{wt} . \%)$ was analyzed in a tensiometer (KSV Sigma 700). After analysis of the influence of components, the ink was formulated with 0.5 wt.\% $\mathrm{TiO}_{2}$ aerogel, 79 wt.\% aqueous solution with $\mathrm{pH} 9$ (distilled water and $\mathrm{NH}_{4} \mathrm{OH}$ ). The prepared suspensions were dispersed by high intensity ultrasound (US, VCX 750, Sonics \& Materials) during $10 \mathrm{~min}$. Finally, the formulation was completed by adding $20 \mathrm{wt} \%$ glycerol, which was reported by Kuscer et al. [8] as a compound that accelerates the drying of the ink and also increases the viscosity. To adjust the surface tension, $0.5 \mathrm{wt} . \%$ Triton $\mathrm{X}-100$ was added to the ink. To evaluate the interaction between the ink and the printing substrate, the contact angle was measured in a goniometer (OCA-15 l, Data Physics).

The printer used in in this work was a Dimatix DMP2800 (Fujifilm Dimatix). The printing process started by inserting the ink in the printer cartridge, passing it through a $0.2 \mu \mathrm{m}$ filter, followed by conventional ultrasonic homogenization for $10 \mathrm{~min}$. Glass substrates coated with indium tin oxide (ITO) were properly cleaned and dried before fixing them in the printer platform. To adjust the printing parameters, the process began with the impression of isolated drops of approximately $10 \mathrm{pL}$ at room temperature. Then, the drop diameter was observed by a drop-watch camera system of the printer. From the measured diameter, it was possible to determine the appropriated drop spacing range for printing uniform lines. After adjustment of the printing parameters, the films were printed in square patterns measuring approximately $1 \times 1 \mathrm{~cm}$, with 1 to 3 layers, in order to verify the coating capacity and the quality of the formed film. Finally, the printed samples were heat treated at $400^{\circ} \mathrm{C}$ during $1 \mathrm{~h}$ for decomposition of additives and densification of the printed layers. For comparison, a layer of a commercial $\mathrm{TiO}_{2}$ paste (average particle size of $20 \mathrm{~nm}$ ) diluted in ethanol, in a ratio of $2: 7$ (wt.\%), was deposited on top of the ITO-glass, by spin coating, at $4000 \mathrm{rpm}$, for 30 seconds and also heat-treated at $400^{\circ} \mathrm{C}$ for $1 \mathrm{~h}$. Printed samples were characterized by image through scanning electron microscopy with field emission (SEM-FEG, JSM-6701F, JEOL). The electrical properties of the printed nanostructured $\mathrm{TiO}_{2}$ layers were evaluated 
through the characteristic $I-V$ curves using a high precision semiconductor analyzer (SMU, Agilent, B2912A). Sheet resistance of the samples was obtained through the fourprobe method using a lab-built test fixture connected to the SMU. All measurements were performed at ambient temperature in triplicate.

\section{Results and Discussion}

Figures 1(a) and 1(b) show TEM micrographs of a $\mathrm{TiO}_{2}$ aerogel. The sample exhibits typical aerogel features such as small interconnected particles with sizes ranging from $10 \mathrm{~nm}$ to $30 \mathrm{~nm}$ that form a solid network with high porosity (Figure 1(a)). Even after grinding and dispersing the $50 \times 150 \mathrm{~nm}$ structure preserves the aerogel morphology (Figure 1(b)). The surface area of the calcined aerogel powder was determined by BET as $103 \mathrm{~m}^{2} / \mathrm{g}$. Figure 1(c) shows the X-ray diffraction pattern of the produced aerogel after calcination. Peaks related to the anatase phase of $\mathrm{TiO}_{2}$ were detected (JCPDS card 89-4921) and the relative wide peaks reveal that the material is nanocrystalline [11-14], with an average crystallite size of $7.6 \mathrm{~nm}$, estimated through the Scherrer equation [15]. Anatase is usually a more desirable phase of $\mathrm{TiO}_{2}$ for use in electronic and optoelectronic applications, like photovoltaic solar cells, due to its higher electron mobility, lower deposition temperature, lower dielectric constant, and lower bulk density $[16,17]$.

Figure 2 shows the particle size distribution of the $\mathrm{TiO}_{2}$ aerogel after dispersion under high intensity sonication for $1,3,5,7$, and $10 \mathrm{~min}$. It is possible to note that within a few minutes of ultrasound irradiation, a considerable reduction in particle size occurs. This can also be seen in Table 1, which presents $D 10, D 50$, and $D 90$ values after US processing. The high intensity ultrasound is very efficient in dispersing process.

Liang and $\mathrm{Lu}$ [18] reported zeta potential studies in function of $\mathrm{pH}$ and demonstrated that the isoelectric point of $\mathrm{TiO}_{2}$ occurs near $\mathrm{pH}$ 6. The isoelectric point is a parameter of great importance for stability studies suspensions because, at this point, the surface potential of the particles is null and agglomeration occurs between the particles. According to the study, the $\mathrm{pH}$ values that promote increased stability of the suspension occur at $\mathrm{pH}$ lower than 3 or higher than 8 [18]. For this study we chose $\mathrm{pH} 9$, which is maximum value recommended by the printer manufacturers. The $\mathrm{pH}$ of $\mathrm{TiO}_{2}$ aqueous solutions for highly negative zeta potential (typically $-30 \mathrm{mV}$ for stable solutions) should be higher than 8 $[6,19]$. The suspension prepared using $\mathrm{TiO}_{2}$ aerogel nanoparticles presented zeta potential of $-38.5 \mathrm{mV}$, which indicate a good condition for the suspensions stability. The significant difference of $D 90$ between 7 and $10 \mathrm{~min}$ is due to a range of sizes wherein a very small amount of particles was recorded. It is observed that there are two major populations of different particle sizes, and the sample processed for $10 \mathrm{~min}$ showed $90 \%$ particles with diameter of less than $119 \mathrm{~nm}$, mostly belonging to the population of smaller particles.

The adjustment of the ink viscosity was performed with the use of different concentrations of glycerol. Figure 3(a) shows the ink viscosity as a function of the glycerol content ranging between 5 and $30 \mathrm{wt} . \%$. The addition of glycerol increased the solution viscosity, but the values obtained with 30 wt.\% glycerol are still lower than the viscosity range recommended by the printer manufacturer $(10-12 \mathrm{mPa} \cdot \mathrm{s})$ [20]. However, a good printability depends not only on the viscosity but also on other properties of the ink such as surface tension, density, and cartridge nozzle size. To examine the influence of the surfactant on the surface tension, inks containing $20 \mathrm{wt} . \%$ glycerol were prepared with $0,0.3$, 0.5 , and 1 wt.\% surfactant (Figure 3(b)). Surface tension is a very important parameter for this process as it directly influences the size and shape of the ink drop. Here, the surface tension was adjusted by the use of a nonionic surfactant, Triton X-100 [7]. When a surfactant is dissolved in water, the surface tension of the solution is reduced. Increasing the surfactant concentration will provide a higher number of molecules on the surface, reducing the surface tension of the solution. However, this reduction in surface tension is limited, reaching a constant value above 0.3 wt. $\%$ surfactant. This limitation occurs because, by increasing the additive concentration, the molecules occupy all the waterair interface, reaching the critical micelle concentration (CMC) and, after this point, the concentration of surfactant no longer reflects in the reduction of surface tension $[21,22]$. The minimum surface tension value for the formulated ink is $32 \mathrm{mN} / \mathrm{m}$, which complies with the requirements of the printer $(32-42 \mathrm{mN} / \mathrm{m})$ [20]. It is important to note that, based on the previous analysis, the addition of glycerol did not change significantly the surface tension. Although the average values for inks without glycerol and inks containing 20 wt.\% glycerol varied, they lied within the deviation in our measurements. On the other hand, the surfactant used (Triton X-100) exhibited virtually no influence on viscosity, due to the low amount used, as also reported in the literature [23].

Another very important parameter for suitable printability is the interaction between the ink and the substrate, which was analyzed by contact angle measurements. Figure 4 shows the contact angle between the ink drops and the ITO-glass substrate, for different compositions. The prepared suspension, initially at $\mathrm{pH} 9.0$ and containing only $\mathrm{TiO}_{2}$ nanoparticles (Figure 4(a)), exhibited the highest contact angle $\left(\theta=76.3^{\circ}\right)$ due to the high surface tension of $50 \mathrm{mN} / \mathrm{m}$. The ink formulated with $20 \mathrm{wt} \%$ glycerol (Figure 4(b)) showed a slight reduction of the contact angle $\left(\theta=71.9^{\circ}\right)$. Finally, when adding $0.5 \mathrm{wt} . \%$ surfactant (Figure 4(c)), a considerable reduction of surface tension occurred $(32 \mathrm{mN} / \mathrm{m})$, corresponding then to the lowest contact angle $\left(\theta=18.6^{\circ}\right)$. The printing process started with filtration, cartridge filling, and homogenization of ink in conventional ultrasound. In order to obtain continuous and uniform printed lines, it is necessary to define the appropriate drop spacing that allows adjacent droplets to interact and coalesce, resulting in a smooth deposited surface [24]. The image of Figure 4(b) was obtained by the printer camera and shows the drops printed separately to obtain the droplet size measurements. The average droplet size from three measurements was $52.6 \mu \mathrm{m}$. 


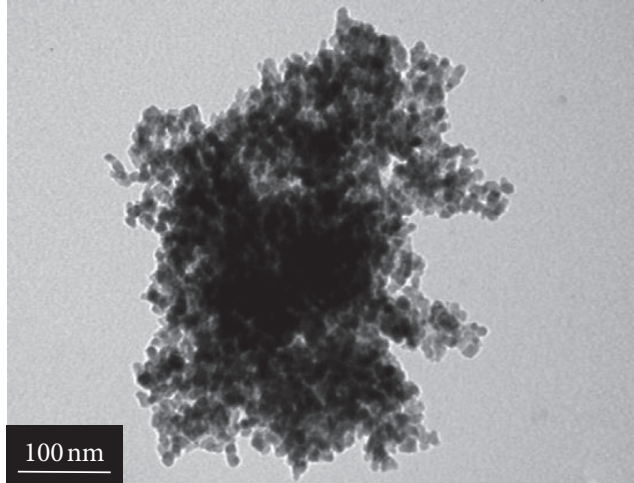

(a)

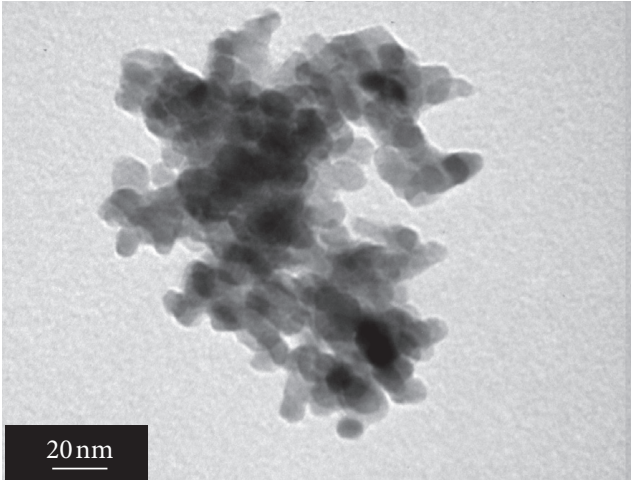

(b)

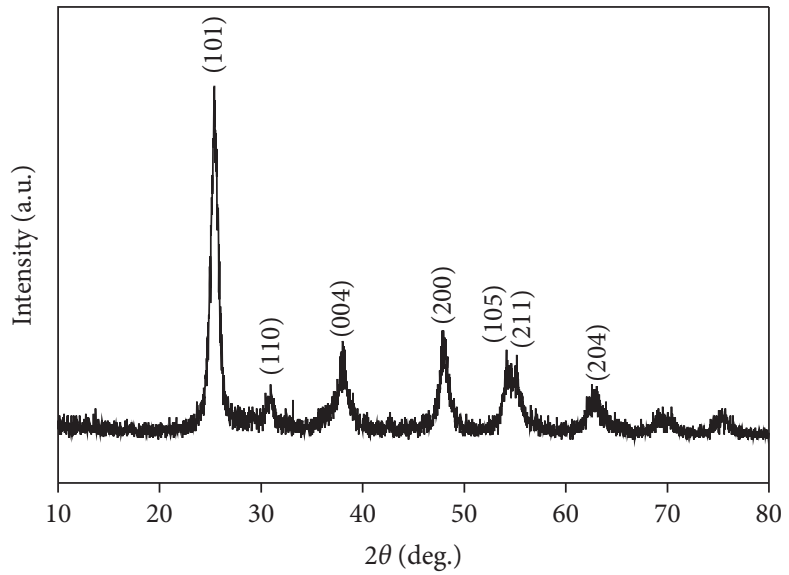

(c)

FIgURE 1: (a) $\mathrm{TiO}_{2}$ aerogel after calcination at $400^{\circ} \mathrm{C}$ for $4 \mathrm{~h}$. (b) Bright-field TEM micrographs of the aerogel nanostructure with different magnifications. (c) X-ray diffraction spectrum.

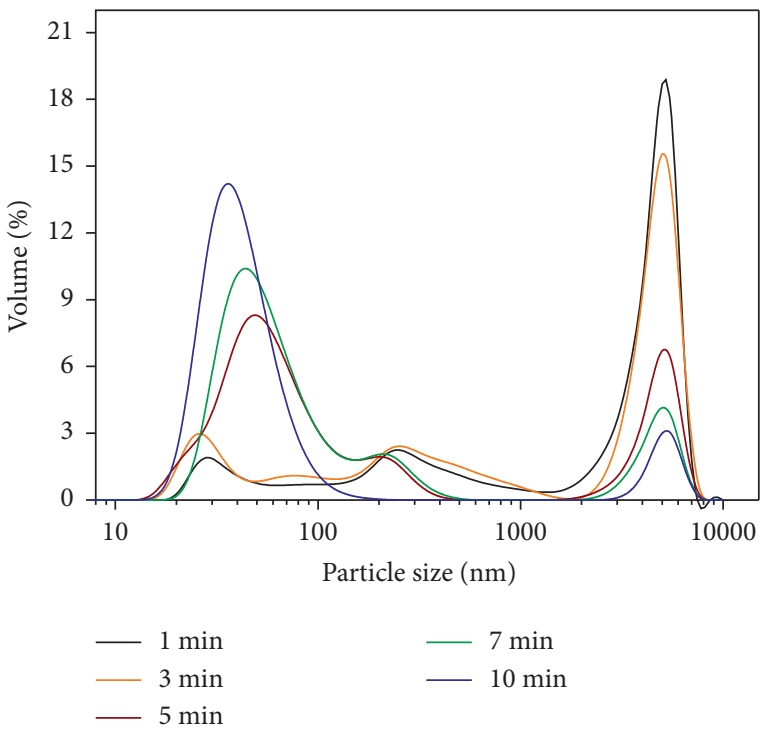

Figure 2: Particle size distribution curves for different processing times in high intensity ultrasound.

Drop spreading velocity and drying kinetics of the ink are also important parameters, since they define the drop spacing and, finally, the printed critical dimension. Drying kinetics involves not only evaporation of the solvent, but also other phenomena associated with the ink formulation itself and its interaction with the substrate, like wetting and diffusion, which in turn could determine the final printing quality [25]. The minimum drop spacing for drop/line stability was reported by Duineveld [26] and it is a dynamic function of the transverse velocity of the printing device relative to the substrate, which in turn depends on the fluid viscosity and the surface tension. Through surface tension and contact angle measurements, a drop spreading velocity of $47.6 \mathrm{~cm} / \mathrm{s}$ and a contact angle variation rate of $1.32 \%$ in average were estimated [27].

In order to analyze the printability of the ink, the inverse Ohnesorge number $(Z)$ was calculated by the following equation, which considers ink and printer characteristics $[8,28,29]$ :

$$
Z=(\alpha \rho \gamma) \frac{1}{2 / \eta},
$$

where $\alpha$ corresponds to the nozzle diameter; $\rho$ is the ink density; $\gamma$ is the ink surface tension; and $\eta$ is the viscosity of the ink. The values used for calculation are presented in Table 2. According to Jang et al. [29], $Z$ values considered adequate to obtain a good printability are between 4 and 14, 
TABLE 1: Values of $D 10, D 50$, and $D 90$ for the samples dispersed in high intensity ultrasound.

\begin{tabular}{lccc}
\hline US time $(\mathrm{min})$ & $D 10(\mathrm{~nm})$ & $D 50(\mathrm{~nm})$ & $D 90(\mathrm{~nm})$ \\
\hline 1 & 72.0 & 3703.9 & 5403.2 \\
3 & 31.5 & 3385.9 & 5350.1 \\
5 & 29.2 & 66.2 & 4762.6 \\
7 & 30.6 & 56.3 & 4137.0 \\
10 & 24.2 & 37.8 & 119.3 \\
\hline
\end{tabular}

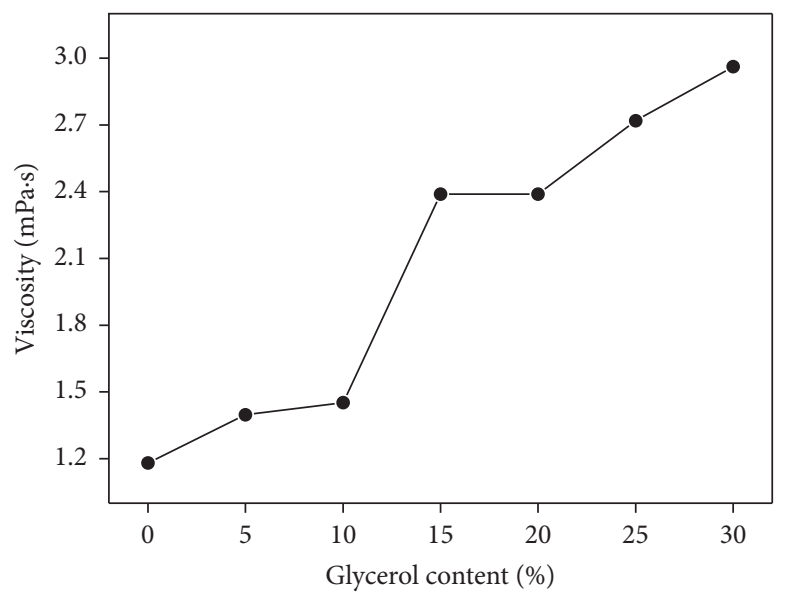

(a)

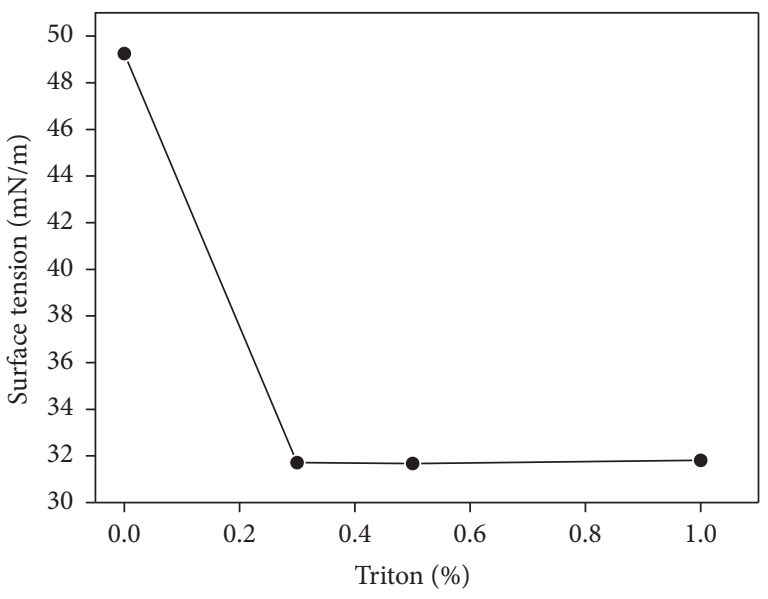

(b)

Figure 3: Influence of additives on ink properties. (a) Influence of glycerol content on viscosity. (b) Influence of Triton X-100 content on the surface tension.

which predict that the ink is capable of being printed and can provide a good printing quality.

rom the droplet size measurements, the drop spacing can be defined as the distance from the center of a drop to the center of another drop, measured in $X$ and $Y$. It is estimated that the spacing between drops to about half the drop diameter is sufficient to obtain a good resolution. However, it is necessary to experimentally determine the best value, since the resolution also depends on the properties of the ink and its interaction with the substrate. Figure 5(a) shows printed lines with drop spacing between $17,19,22,25$, and $28 \mu \mathrm{m}$. Drop spacing of 17,19 , and $28 \mu \mathrm{m}$ exhibited better uniformity in thickness when compared to the others. However, the printed line with $28 \mu \mathrm{m}$ of drop spacing showed a reduction in thickness due to the large distance between the droplets. The lines with 22 and $25 \mu \mathrm{m}$ showed a high irregularity in thickness, which could affect the printing quality. The lines with 17 and $19 \mu \mathrm{m}$ of drop spacing resulted in more uniform lines. Therefore, the spacing of $17 \mu \mathrm{m}$ was chosen for layer printing due to the highest quality of the printed line. Ink behavior was also verified for printing lines of 1 to 4 pixels thick, that is, with 1 to 4 drops deposited in thickness (Figure 5(b)). For the lines with different thicknesses, it can be noted that a larger number of lines cause ink buildup in certain regions. This is a result of the attraction between the droplets due to surface tension. It is important to mention that these images were obtained immediately after printing, when the ink was not completely dried. As the inks are water-based, we evaluated different drying conditions were preliminarily tested. Inks heated at temperatures higher than $80^{\circ} \mathrm{C}$ formed bubbles, which damaged the printed patterns. For lower temperatures, i.e., room temperature, no visible changes in dimensions occurred after drying.

Figure 6 shows SEM micrographs of the printed layers. In the images of Figure 6(a), it is possible to observe that the printed film with a single layer did not form a uniform coating due to the low concentration of aerogel particles. However, films with two and three layers fully coated the printed area (Figures 6(b) and 6(c)). Higher magnification images (Figures 6(d)-6(f)) revealed that the film with 1 layer corresponded to only small clusters of nanoparticles, which resulted in a nonuniform coating (Figure 6(d)). This image, however, allows analyzing the shape and size of the agglomerates, since they remain separated even after deposition. The printed film with two layers (Figure 6(e)) provides a larger printed surface with partially interconnected pores and grains with sizes ranging from $10 \mathrm{~nm}$ to $50 \mathrm{~nm}$. The printed film with 3 layers (Figure 6(f)), however, exhibited a reduction in porosity and an increase in the grain size. For optoelectronic applications, the two most important properties for the $\mathrm{TiO}_{2}$ layer are the particle size and the surface porosity. The smaller the particle size, 


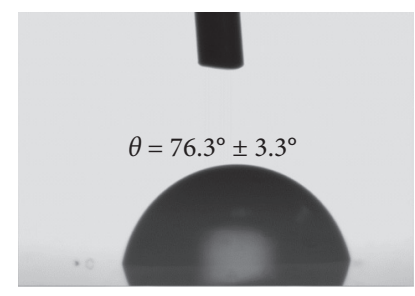

(a)

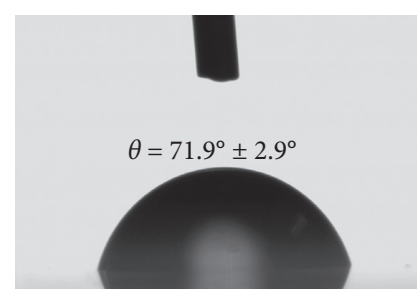

(b)

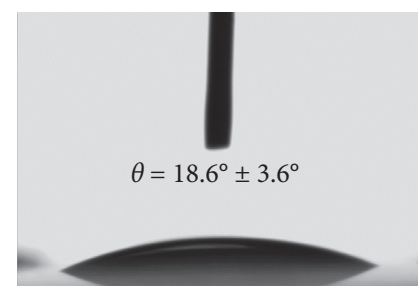

(c)

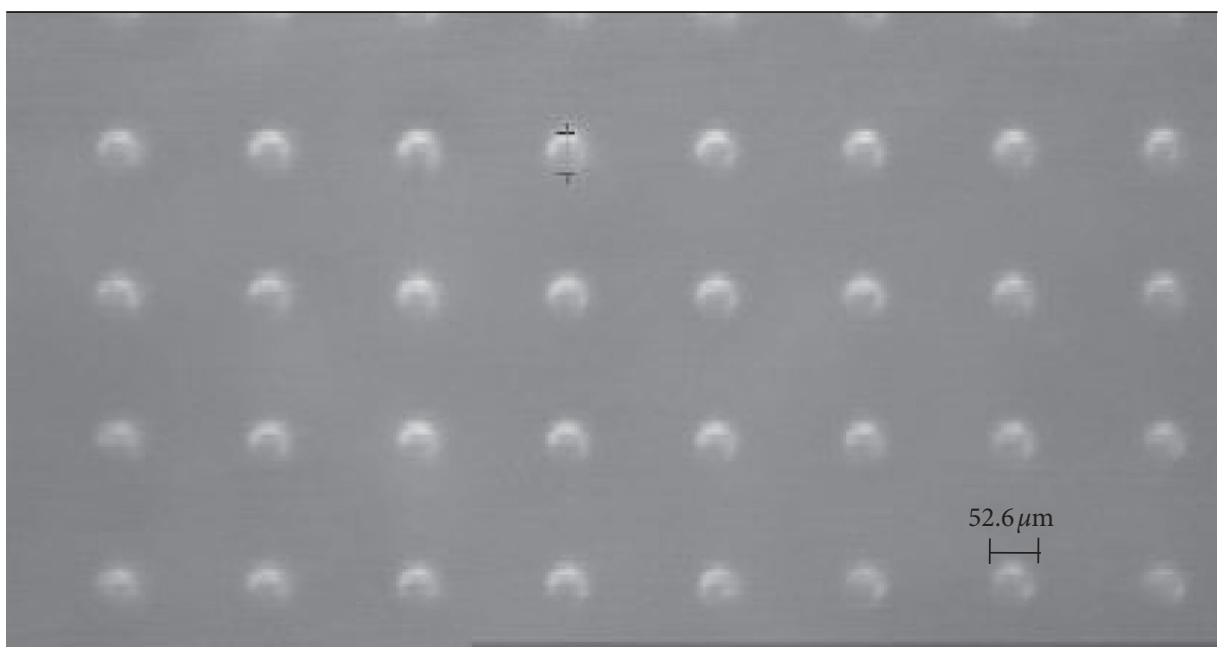

(d)

Figure 4: Contact angle between the ITO-glass substrate and the inks formulated with (a) $0.5 \% \mathrm{TiO}_{2}$; (b) $0.5 \% \mathrm{TiO}_{2}$ and $20 \%$ glycerol; (c) $0.5 \% \mathrm{TiO}_{2}, 20 \%$ glycerol, and $0.5 \%$ Triton X-100; and (d) printed isolated drops for drop size measurement.

TABLe 2: Values used for the calculation of the inverse Ohnesorge number $(Z)$.

\begin{tabular}{lc}
\hline Parameter & Value \\
\hline Nozzle diameter $(\alpha)$ & $21.5 \mu \mathrm{m}$ \\
Ink density $(\rho)$ & $0.983 \mathrm{~g} / \mathrm{ml}$ \\
Surface tension $(\gamma)$ & $32 \mathrm{mN} / \mathrm{m}$ \\
Viscosity $(\eta)$ & $2.3 \mathrm{mPa} \cdot \mathrm{s}$ \\
Inverse Ohnesorge number $(Z)$ & 11.3 \\
\hline
\end{tabular}

the higher the surface porosity resulting in larger surface area for coupling of the dye and penetration of electrolyte [1].

The efficient transport of electrons in a semiconductor nanocrystalline is highly dependent on the connectivity between individual particles and also on the contact area between the semiconductor layer and the substrate. A dense layer of $\mathrm{TiO}_{2}$ favors these film properties but, however, reduces the surface area of the deposited layer, reducing the amount of dye molecules to be adhered to the material. On the other hand, a lower connectivity between the particles reduces the charge carrier mobility over the semiconductor film. By analyzing the images obtained in this study, it is considered that the ink formulated from $\mathrm{TiO}_{2}$ aerogel associated with the inkjet printing process showed adequate features for printed electronics applications, since the printed films are formed by a highly interconnected $\mathrm{TiO}_{2}$ network with homogeneous size distribution over the surface.
Figure 7 shows the $V-I$ curves of the printed $\mathrm{TiO}_{2}$ aerogel layers in comparison with a commercial $\mathrm{TiO}_{2}$ paste deposited on ITO-glass substrates. A typical resistive behavior is displayed by all samples, characterized by the linear dependence of the current with the applied voltage.

The inset reveals the small difference between both 2 and 3 printed layers. The sheet resistance was calculated withfd2

$$
\rho=\frac{\pi}{\ln 2(V / I)}\left[\frac{\Omega}{\square}\right],
$$

where $I$ is current applied and $V$ is the measured voltage. The sheet resistance of the materials is shown in Table 3.

As shown by the curves, the difference in resistance between the 2 and 3 printed layers is small. Comparing to commercial $\mathrm{TiO}_{2}$ paste the printed $\mathrm{TiO}_{2}$ aerogel layers are more conductive. Although ITO is considered a conductive film, the printed aerogel layers exhibit sheet resistance only $50 \%$ higher than ITO. 


\begin{tabular}{|c|c|c|}
\hline Drop spacing & Line thickness & Printer camera images \\
\hline $17 \mu \mathrm{m}$ & $78.2 \mu \mathrm{m}$ & \\
\hline $19 \mu \mathrm{m}$ & $67.6 \mu \mathrm{m}$ & \\
\hline & & \\
\hline $2 \mu \mathrm{m}$ & Irregular & \\
\hline & $4.5 \mu \mathrm{m}-88 \mu \mathrm{m}$ & \\
\hline $2 \mu \mathrm{m}$ & Irregular & \\
\hline & & \\
\hline & & \\
\hline & & \\
\hline
\end{tabular}

(a)

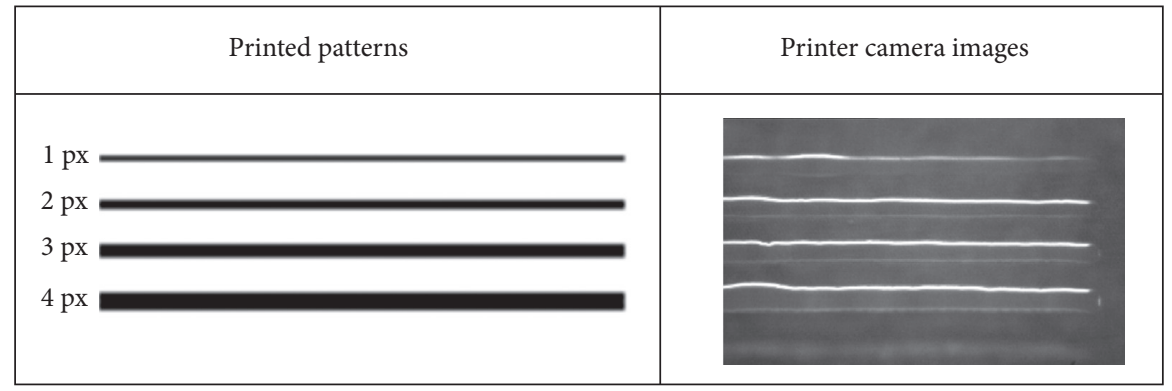

(b)

FIgure 5: (a) Printed lines with different drop spacing values. (b) Printed lines with different thicknesses.

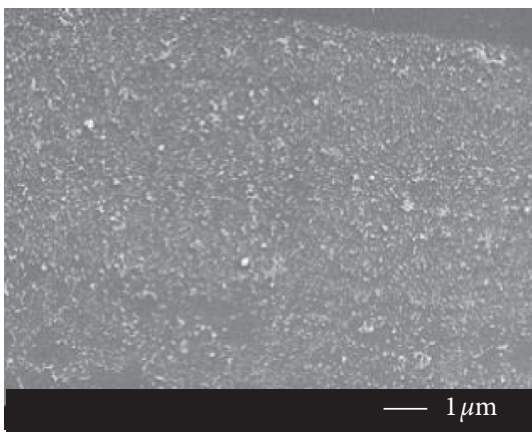

(a)

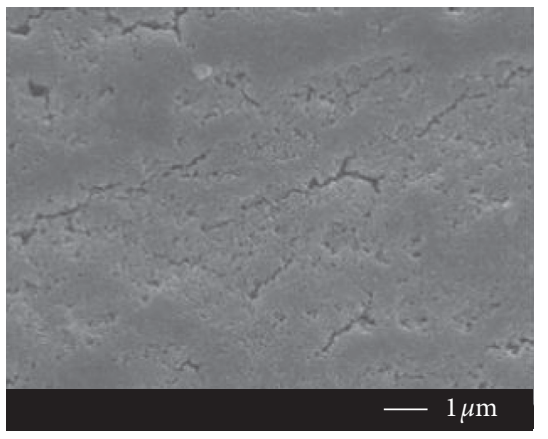

(b)

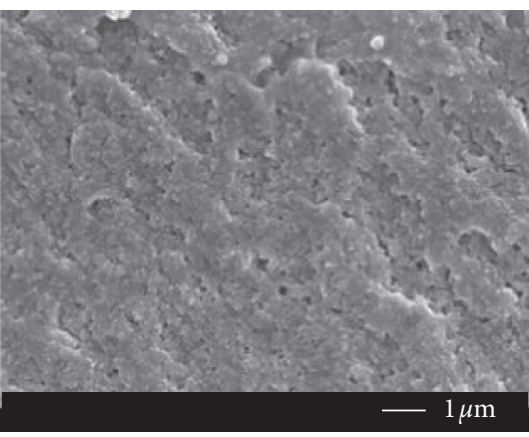

(c)

Figure 6: Continued. 


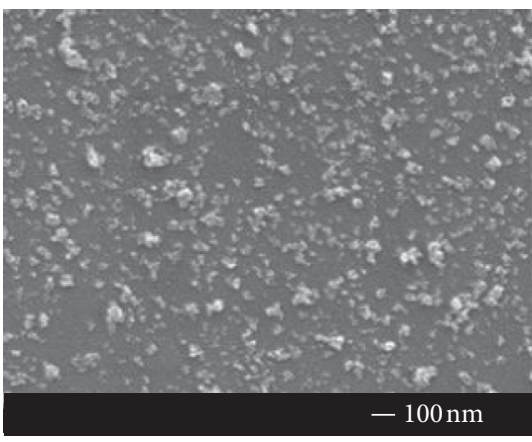

(d)

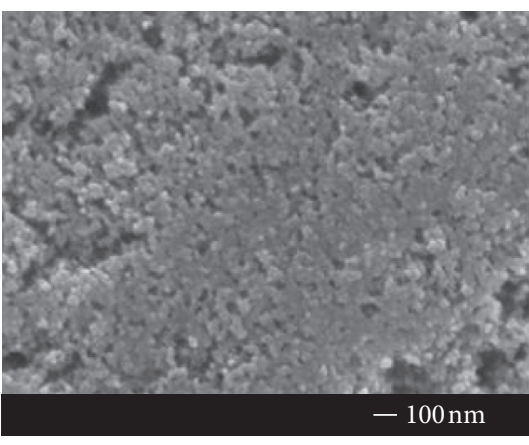

(e)

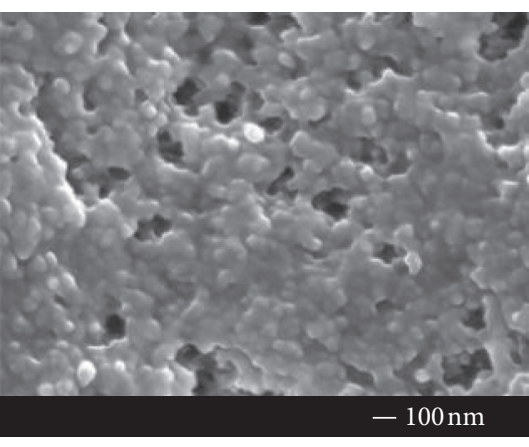

(f)

FiguRe 6: SEM micrographs of the printed films with (a) 1 layer (10,000x), (b) 2 layers (10,000x), (c) 3 layers (10,000x), (d) 1 layer (50,000x), (e) 2 layers $(50,000 \mathrm{x})$, and (f) 3 layers (50,000x).

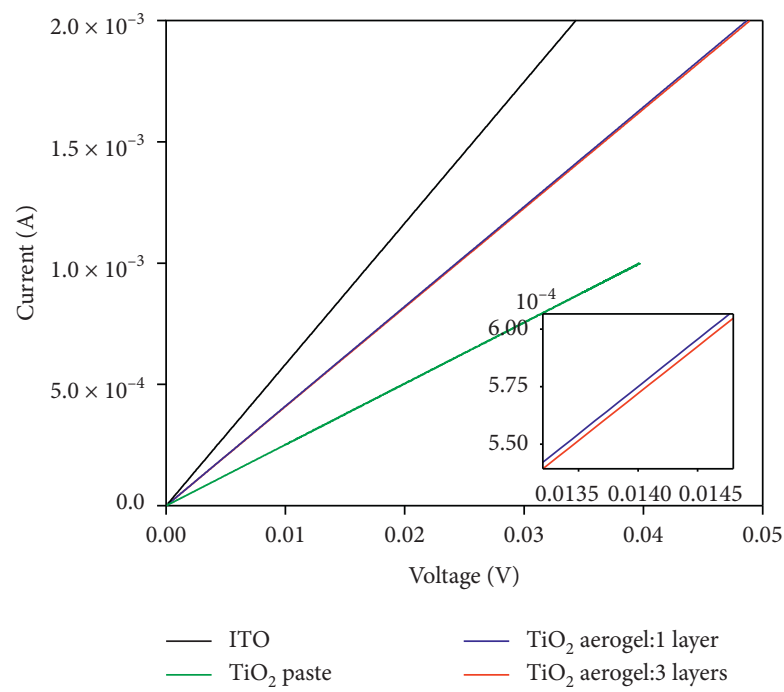

Figure 7: $V-I$ curves of the printed $\mathrm{TiO}_{2}$ aerogel layers in comparison with a commercial $\mathrm{TiO}_{2}$ paste deposited on ITO-glass substrates.

TABLE 3: Sheet resistance of the deposited materials on ITO.

\begin{tabular}{lc}
\hline Material & Sheet resistance $(\Omega / \square)$ \\
\hline ITO & $77.0 \pm 1.1$ \\
$\mathrm{TiO}_{2}$ paste & $180.6 \pm 0.7$ \\
$\mathrm{TiO}_{2}$ aerogel (1 layer) & $104.2 \pm 1.9$ \\
$\mathrm{TiO}_{2}$ aerogel (3 layers) & $114.0 \pm 1.8$ \\
\hline
\end{tabular}

\section{Conclusions}

Stable colloidal processing of $\mathrm{TiO}_{2}$ aerogel, followed by dispersion in high intensity ultrasonic processor, was carried out successfully. The adjustment of the viscosity and the surface tension of the suspensions by adding glycerol and Triton X-100, respectively, at a high $\mathrm{pH}$ solution resulted in inks with the required properties for inkjet printing process. The formulated inks exhibited satisfactory printability, as predicted by the inverse number of Ohnesorge, and allowed printing uniform lines. Electrical measurements revealed a sheet resistance in order of hundreds of $\Omega / \square$. By analyzing
$1 \times 1 \mathrm{~cm}^{2}$ printed films, it is possible to conclude that the 3 layered printed film presented adequate characteristics for printed electronic and optoelectronic devices.

\section{Data Availability}

All data used to support the findings of this study are included within the article.

\section{Conflicts of Interest}

The authors declare that there are no conflicts of interest regarding the publication of this paper.

\section{Acknowledgments}

The authors thank the Central Laboratory of Electronic Microscopy (LCME at UFSC). The following laboratories at UFSC are also acknowledged: LDRX, CERMAT, and LMPT. This work was funded by National Council for Scientific and Technological Development (CNPq/Brazil) and Coordination for the Improvement of Higher Level Personnel 
(CAPES/Brazil) (Finance Code 001, Project no. PRINT 88881.310728/2018-01).

\section{References}

[1] A. J. Huckaba, Y. Lee, R. Xia et al., "Inkjet-printed mesoporous $\mathrm{TiO}_{2}$ and perovskite layers for high efficiency perovskite solar cells," Energy Technology, vol. 7, pp. 317-324, 2019.

[2] J. Burschka, N. Pellet, S.-J. Moon et al., "Sequential deposition as a route to high-performance perovskite-sensitized solar cells," Nature, vol. 499, no. 7458, pp. 316-319, 2013.

[3] Q. Zhang and G. Cao, "Nanostructured photoelectrodes for dye-sensitized solar cells," Nano Today, vol. 6, no. 1, pp. 91-109, 2011.

[4] G. K. Pinheiro, R. B. Serpa, L. V. de Souza, M. L. Sartorelli, F. T. Reis, and C. R. Rambo, "Increasing incident photon to current efficiency of perovskite solar cells through $\mathrm{TiO}_{2}$ aerogel-based nanostructured layers," Colloids and Surfaces A: Physicochemical and Engineering Aspects, vol. 527, pp. 89-94, 2017.

[5] I. Bernacka-Wojcik, P. J. Wojcik, H. Aguas, E. Fortunato, and R. Martins, "Inkjet printed highly porous $\mathrm{TiO}_{2}$ films for improved electrical properties of photoanode," Journal of Colloid and Interface Science, vol. 465, pp. 208-214, 2016.

[6] W. Y. Padrón-Hernández, M. C. Ceballos-Chuc, D. Pourjafari et al., "Stable inks for inkjet printing of $\mathrm{TiO}_{2}$ thin films," Materials Science in Semiconductor Processing, vol. 81, pp. 75-81, 2018.

[7] E. B. Duoss, M. Twardowski, and J. A. Lewis, "Sol-gel inks for direct-write assembly of functional oxides," Advanced Materials, vol. 19, no. 21, pp. 3485-3489, 2007.

[8] D. Kuscer, G. Stavber, G. Trefalt, and M. Kosec, "Formulation of an aqueous titania suspension and its patterning with inkjet printing technology," Journal of the American Ceramic Society, vol. 95, no. 2, pp. 487-493, 2012.

[9] K. Sato, J.-G. Li, H. Kamiya, and T. Ishigaki, "Ultrasonic dispersion of $\mathrm{TiO} 2$ Nanoparticles in aqueous suspension," Journal of the American Ceramic Society, vol. 91, no. 8, pp. 2481-2487, 2008.

[10] J. C. Bernardes, G. K. Pinheiro, D. Muller, E. Latocheski, J. B. Domingos, and C. R. Rambo, "Novel modified nonalkoxide sol-gel synthesis of multiphase high surface area $\mathrm{TiO}_{2}$ aerogels for photocatalysis," Journal of Sol-sGel Science and Technology, vol. 94. , 2020 in Press.

[11] O. Carp, C. L. Huisman, and A. Reller, "Photoinduced reactivity of titanium dioxide," Progress in Solid State Chemistry, vol. 32, no. 1-2, pp. 33-177, 2004.

[12] M. Wright and A. Uddin, "Organic-inorganic hybrid solar cells: a comparative review," Solar Energy Materials and Solar Cells, vol. 107, pp. 87-111, 2012.

[13] K. Thamaphat, P. Limsuwan, and B. Ngotawornchai, "Phase characterization of $\mathrm{TiO}_{2}$ powder by XRD and TEM," Kasetsart Journal-Natural Science, vol. 42, pp. 357-361, 2008.

[14] S. U. Ekar, G. Shekhar, Y. B. Khollam et al., "Green synthesis and dye-sensitized solar cell application of rutile and anatase $\mathrm{TiO}_{2}$ nanorods," Journal of Solid State Electrochemistry, vol. 21, pp. 1-6, 2017.

[15] A. R. Stokes and A. J. C. Wilson, "A method of calculating the integral breadths of Debye-Scherrer lines," Mathematical Proceedings of the Cambridge Philosophical Society, vol. 38, no. 3, pp. 313-322, 1942.
[16] J. Xu, L. Li, Y. Yan et al., "Synthesis and photoluminescence of well-dispersible anatase $\mathrm{TiO} 2$ nanoparticles," Journal of Colloid and Interface Science, vol. 318, no. 1, pp. 29-34, 2008.

[17] J. G. d. Santos, T. Ogasawara, and R. A. Corrêa, "Synthesis of mesoporous titania in rutile phase with pore-stable structure," Brazilian Journal of Chemical Engineering, vol. 26, no. 3, pp. 555-561, 2009.

[18] Y. Liang and K. Lu, "Titania nanoparticle suspension for fabrication of micrometer feature arrays via a templateassisted approach," International Journal of Applied Ceramic Technology, vol. 9, no. 5, pp. 911-919, 2012.

[19] X. N. Yang and F. Y. Cui, "Stability of nano-sized titanium dioxide in an aqueous environment: effects of $\mathrm{pH}$, dissolved organic matter and divalent cations," Water Science and Technology, vol. 68, no. 2, pp. 276-282, 2013.

[20] Fujifilm-Dimatix, Jettable Fluid Formulation Guidelines, Fujifilm-Dimatix, Lebanon, NH, USA, 2013.

[21] C. H. Chang and E. I. Franses, "Adsorption dynamics of surfactants at the air/water interface: a critical review of mathematical models, data, and mechanisms," Colloids and Surfaces A: Physicochemical and Engineering Aspects, vol. 100, pp. 1-45, 1995.

[22] C. S. Chern, Principles and Applications of Emulsion Polymerization, Wiley, Hoboken, NJ, USA, 2008.

[23] Y.-J. Yang, D. S. Corti, and E. I. Franses, "Effect of Triton $\mathrm{X}-100$ on the stability of titania nanoparticles against agglomeration and sedimentation: a masked depletion interaction," Colloids and Surfaces A: Physicochemical and Engineering Aspects, vol. 516, pp. 296-304, 2017.

[24] Y. Galagan, E. W. C. Coenen, S. Sabik et al., "Evaluation of ink-jet printed current collecting grids and busbars for ITOfree organic solar cells," Solar Energy Materials and Solar Cells, vol. 104, pp. 32-38, 2012.

[25] J. Kettle, T. Lamminmäki, and P. Gane, "A review of modified surfaces for high speed inkjet coating," Surface and Coatings Technology, vol. 204, no. 12-13, pp. 2103-2109, 2010.

[26] C. Duineveld, "The stability of ink-jet printed lines of liquid with zero receding contact angle on a homogeneous substrate," Journal of Fluid Mechanics, vol. 477, pp. 175-200, 2003.

[27] T. Lim, S. Han, J. Chung, J. T. Chung, S. Ko, and C. P. Grigoropoulos, "Experimental study on spreading and evaporation of inkjet printed pico-liter droplet on a heated substrate," International Journal of Heat and Mass Transfer, vol. 52, no. 1-2, pp. 431-441, 2009.

[28] J. E. Fromm, "Numerical calculation of the fluid dynamics of drop-on-demand jets," IBM Journal of Research and Development, vol. 28, no. 3, pp. 322-333, 1984.

[29] D. Jang, D. Kim, and J. Moon, "Influence of fluid physical properties on ink-jet printability," Langmuir, vol. 25, pp. 2629-2635, 2009. 